\title{
Estimativas da área foliar e da biomassa aérea da pupunheira por meio de relações alométricas
}

\author{
Adriana Ramosi'; Marilene Leão Alves Bovi²; Marcos Vinícius Folegatti³; Adriano Valentim Diotto ${ }^{4}$ \\ ${ }^{1}$ Universidade Estadual de Santa Cruz, Rod Ilhéus-Itabuna, km 16, 45662-000 Ilhéus-BA; ${ }^{2}$ in memoriam; ${ }^{3}$ ESALQ, C. postal 9, 13418 - \\ 900 Piracicaba-SP; ${ }^{4}$ Suproser, Rua Igarassu, 108, 13484-023 Limeira-SP; aramos2004@uol.com.br; mvfolegga@esalq.usp.br; \\ avdiotto@yahoo.com.br
}

\begin{abstract}
RESUMO
Relações alométricas para estimativa da área foliar e da biomassa total em pupunheiras (Bactris gasipaes Kunth) têm sido empregadas por diversos autores, sendo úteis especialmente em pesquisas relacionadas à fisiologia vegetal. No entanto, área foliar e biomassa aérea são características de elevada plasticidade, podendo variar acentuadamente por causas genéticas e edafoclimáticas. O presente trabalho foi desenvolvido com o objetivo de identificar as equações mais adequadas para determinação da área foliar e da biomassa aérea (foliar e total) da pupunheira, em condições de limitações sazonais hídricas e térmicas. Foram utilizadas 14 plantas de pupunheiras da raça Putumayo (Yurimaguas), cultivadas no espaçamento de 2,0 $\mathrm{m} \times 1,0 \mathrm{~m}$. Foram mensurados altura e diâmetro da haste principal, número de folhas, comprimento, espessura e largura da ráquis foliar de plantas apresentando altura entre 0,37 e 2,00 m, com duas plantas por altura. Obtiveram-se ainda as massas fresca e seca da ráquis, dos folíolos, dos palmitos e dos estipes das plantas. Os dados foram submetidos à análise de regressão e ajustes de equações. A equação para determinação da área foliar da pupunheira foi obtida pela regressão para o peso seco dos folíolos. Dentre os modelos testados, as equações não lineares do tipo $Y=a x^{b}$ e $Y=a^{b x}$ apresentaram melhor ajuste $\left(\mathrm{R}^{2}>0,88\right)$. Os valores de área foliar, biomassa foliar e biomassa aérea total variaram de 0,84 a 14,06 $\mathrm{m}^{2}$, de 0,78 a 2,45 kg planta $^{-1}$ e de 0,14 a $4,44 \mathrm{~kg}_{\text {planta }}{ }^{-1}$, respectivamente. Dentre as características avaliadas, a altura da haste e a espessura da ráquis foliar se mostraram as mais adequadas para estimativa da área foliar, da biomassa foliar e da biomassa aérea total da pupunheira, tanto pela sua facilidade de mensuração, quanto pela sua alta correlação com os demais caracteres.
\end{abstract}

Palavras-chave: Bactris gasipaes, altura, fitomassa, pupunha, relações alométricas.

\begin{abstract}
Leaf area and aboveground biomass estimates in peach palm using allometric relationships
\end{abstract}

Allometric relations for estimation of leaf area and biomass in peach palm (Bactris gasipaes Kunth) are found in literature and are very useful especially in plant physiology research. However, leaf and biomass area parameters are quite variable as a function of genetics and environment. The objective of this work was to identify the most adjustable equations for peach palm leaf area and biomass area, in restricted by hydric and thermic factors. 14 peach palms (Putumayo landrace from Yurimaguas, Peru) were planted in $2 \times 1$ $\mathrm{m}$ spacing. The parameters measured in the field were: main stem height, main stem diameter, leaf number and rachis length and thickness. Fresh and dry mass of rachis, leaflets, palm heart and stem were obtained. Plants selected for this study presented main stem height varying from 0.37 to $2.00 \mathrm{~m}$, with two plants by length. In the laboratory were measured the leaf area and dry matter weight. Equations were fitted using regression analysis. The equation for peach palm leaf area was obtained by regression of leaflets dry weight. Among the tested models, non linear equations of the type $Y=a x^{b}$ and $Y=a^{b x}$ presented better fit $\left(\mathrm{R}^{2}>0.88\right)$. The values of leaf area, leaf biomass and total leaf biomass varied between $0,84-14,06$ $\mathrm{m}^{2}, 0,78-2,45 \mathrm{~kg}$ planta $^{-1}$ and $0,14 \mathrm{a} 4,44 \mathrm{~kg}$ planta $^{-1}$. Among the parameters studied, plant height and rachis thickness were the most suitable for best indirect estimation of leaf area and aboveground biomass in peach palm plants.

Keywords: Bactris gasipaes, height, pejibaye, phytomass, rachis thickness.

(Recebido para publicação em 10 de janeiro de 2007; aceito em 9 de junho de 2008)

\begin{abstract}
A análise de crescimento vegetativo permite conhecer diferenças funcionais e estruturais entre plantas. Possibilita também avaliar o crescimento final da planta como um todo e a contribuição dos diferentes órgãos no crescimento total. Curvas de crescimento, efetuadas com base nesse tipo de análise, são muitas vezes utilizadas para detectar diferenças entre os tratamentos estabelecidos. O crescimento de plantas sob diferentes condições ambientais
\end{abstract}

pode ser mensurado de diversas maneiras, utilizando-se de medidas lineares, de superfície, peso e/ou de número de unidades estruturais. Entre as dimensões lineares, é possível citar a altura da planta, comprimento de ramificações e diâmetro de caules. $\mathrm{O}$ crescimento também pode ser acompanhado a partir de unidades estruturais morfológicas ou anatômicas, como número de ramificações, folhas, flores, frutos e raízes. Estas medidas podem fornecer informa- ções importantes quanto à fenologia e são, muitas vezes, utilizadas para detectar respostas diferenciais dos efeitos de tratamento (Benincasa, 1988).

As medidas de superfície estão relacionadas principalmente à determinação ou estimativa da superfície fotossinteticamente ativa. Dentre elas, está o índice de área foliar (IAF), que é a relação entre a área foliar total e a área do solo sombreada pelas folhas. Métodos indiretos e diretos para a determi- 
nação do IAF das palmeiras vêm sendo empregados (Clement et al., 1985; Lamade, 1997; Martel \& Clement, 1986, 1987). Estudos desenvolvidos por Hartley (1977), em dendezeiro, e por Child (1974), em coqueiro, têm demonstrado que a área foliar está diretamente relacionada à produção de frutos, sendo um importante parâmetro de avaliação da produtividade. Clement et al. (1985) acreditando que esta correlação também poderia ser verdadeira para a pupunheira, empregaram métodos não destrutivos para estimar a área foliar a partir de equações desenvolvidas por Hardon et al. (1969) para o dendezeiro. Os métodos apresentaram coeficientes de regressão muito semelhantes para as equações desenvolvidas para as duas espécies. Entretanto, os autores sugerem pequenas modificações em algumas equações, adaptando-as para seu uso em pupunheiras.

Clement \& Bovi (2000) discutiram métodos para análise de crescimento e produção em pupunheira, propondo a padronização de medidas a serem utilizadas em experimentos agronômicos e genéticos visando à produção de palmito. Dentre as medidas de superfície e massa, os autores sugerem a determinação da área e da biomassa foliar pelo emprego de equações desenvolvidas anteriormente para a pupunheira. Não obstante, afirmam que estas equações devem ser validadas para as condições locais de estudo, uma vez que área foliar e biomassa são parâmetros altamente plásticos (Clement, 1995).

Utilizando pupunheiras da raça Utilis-Tucurrique, material com espinhos, bastante diferente do que vem sendo cultivado no Brasil, Ares et al. (2002) concluíram que o diâmetro da haste principal foi a variável de melhor ajuste para a estimativa da biomassa aérea de pupunheiras com 1,9 a 21 anos de idade, em cultivo na Costa Rica. Recentemente Vega et al. (2004) estudaram a utilização de relações alométricas para estimativa da fitomassa aérea de pupunheiras da raça Putumayo, material inerme e que vem sendo amplamente utilizado no Brasil para a produção comercial de palmito (Bovi, 1998). Utilizando plantas cultivadas em um espaçamento de 2 x $1 \mathrm{~m}$, em Ubatuba, região de maior aptidão para a cultura no estado de São Paulo, Vega et al. (2004) relataram que, devido aos altos coeficientes de determinação encontrados, a fitomassa da pupunheira pode ser estimada de forma precisa pela utilização de algumas relações alométricas. Os autores concluíram que, dentre todos os caracteres avaliados, a altura da haste principal foi o caráter ideal para estimar a fitomassa de pupunheiras em cultivo comercial.

O presente trabalho foi desenvolvido com o objetivo de identificar equações para determinação da área foliar e da biomassa aérea (foliar e total) da pupunheira para as condições de Piracicaba, SP, região onde a espécie está sujeita a limitações hídricas e térmicas.

\section{MATERIAL E MÉTODOS}

O estudo foi conduzido EM área experimental da USP-ESALQ, em

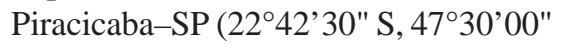
$\mathrm{W}$, altitude de 576 metros), em um Argissolo Vermelho Eutrófico típico. Segundo a classificação climática de Köppen, o clima é do tipo CWa, isto é subtropical úmido, verão chuvoso, e inverno seco. A precipitação média anual é $1247 \mathrm{~mm}$, temperatura média $21,1^{\circ} \mathrm{C}$, umidade relativa média de $74 \%$ e velocidade do vento de $2,2 \mathrm{~m} \mathrm{~s}^{-1}$, com direção E/SE predominantemente (Ometto, 1981). Na área experimental foi instalado um plantio de pupunheira (raça Putumayo, originada em Yurimaguas) em maio de 1999, no espaçamento de $2,0 \mathrm{~m} \times 1,0 \mathrm{~m}$. As plantas foram irrigadas diariamente e fertirrigadas semanalmente $\left(0,08 \mathrm{~kg} \mathrm{planta}^{-1} \mathrm{de} \mathrm{N}\right)$, sendo a lâmina estimada em função do Tanque Classe A ( $100 \%$ da ETo).

Em novembro de 2001, foram utilizadas 14 plantas de pupunheira (30 meses a campo) para estudo das equações de área foliar e biomassa. As plantas selecionadas apresentavam alturas variando entre 0,37 e $2,00 \mathrm{~m}$, como normalmente acontece em cultivos comerciais. Foram utilizadas duas plantas por altura. De cada planta foram mensurados os caracteres da haste principal: altura, diâmetro, número de folhas e, comprimento, largura e espessu- ra da ráquis foliar. Esses dois últimos caracteres foram medidos com o auxílio de paquímetro digital, na folha +2 (segunda folha completamente expandida), na região limite entre o pecíolo e o limbo foliar (início do aparecimento dos folíolos). Em laboratório, foram retiradas todas as folhas da haste principal e todos os folíolos de cada folha, obtendo-se a massa fresca da ráquis e dos folíolos, inclusive da folha flecha. Pesaram-se também os palmitos e os estipes das plantas, que foram cortados em pedaços para facilitar o processo de secagem. Em seguida, todo o material foi levado para a estufa a $60^{\circ} \mathrm{C}$, por quatro dias, pesando-o novamente para obtenção do peso seco.

Antes de serem levados à estufa, os folíolos foram separados em grupos que variaram de 1 a 50 folíolos, sendo obtido o peso fresco de cada grupo. Os folíolos de cada grupo foram desenhados em papel sulfite e recortados para obtenção da área foliar de cada folíolo, empregando-se um medidor de área foliar (Li-Cor area meter, modelo LAI 3000). Este procedimento foi necessário, pois os folíolos da pupunheira tendem a se enrolar quando destacados da ráquis foliar, o que torna imprecisa a determinação da área foliar pelo LAI 3000 quando realizado diretamente sobre o folíolo. A equação para determinação da área foliar da pupunheira foi então obtida pela regressão entre a área foliar (LAI 3000) e o peso seco dos folíolos. O índice de área foliar (IAF) foi estimado pela relação entre a área foliar e o espaçamento. A biomassa foliar foi obtida pela soma dos pesos se$\cos$ dos folíolos e das ráquis. Para o cálculo da biomassa total, acrescentou-se à biomassa foliar o peso seco do estipe e do palmito (Clement; Bovi, 2000).

Foi realizada análise preliminar dos dados visando caracterizar a população amostrada para cada característica estudada. Além da média, calculou-se o coeficiente de variação, seguindo-se os procedimentos de Steel \& Torrie (1980) e utilizando-se o programa SAEG - Sistema para Análises Estatísticas (Universidade Federal de Viçosa, 1993). Os dados foram estudados por análise de regressão e ajuste de equações, tendo como variável dependente as caracterís- 

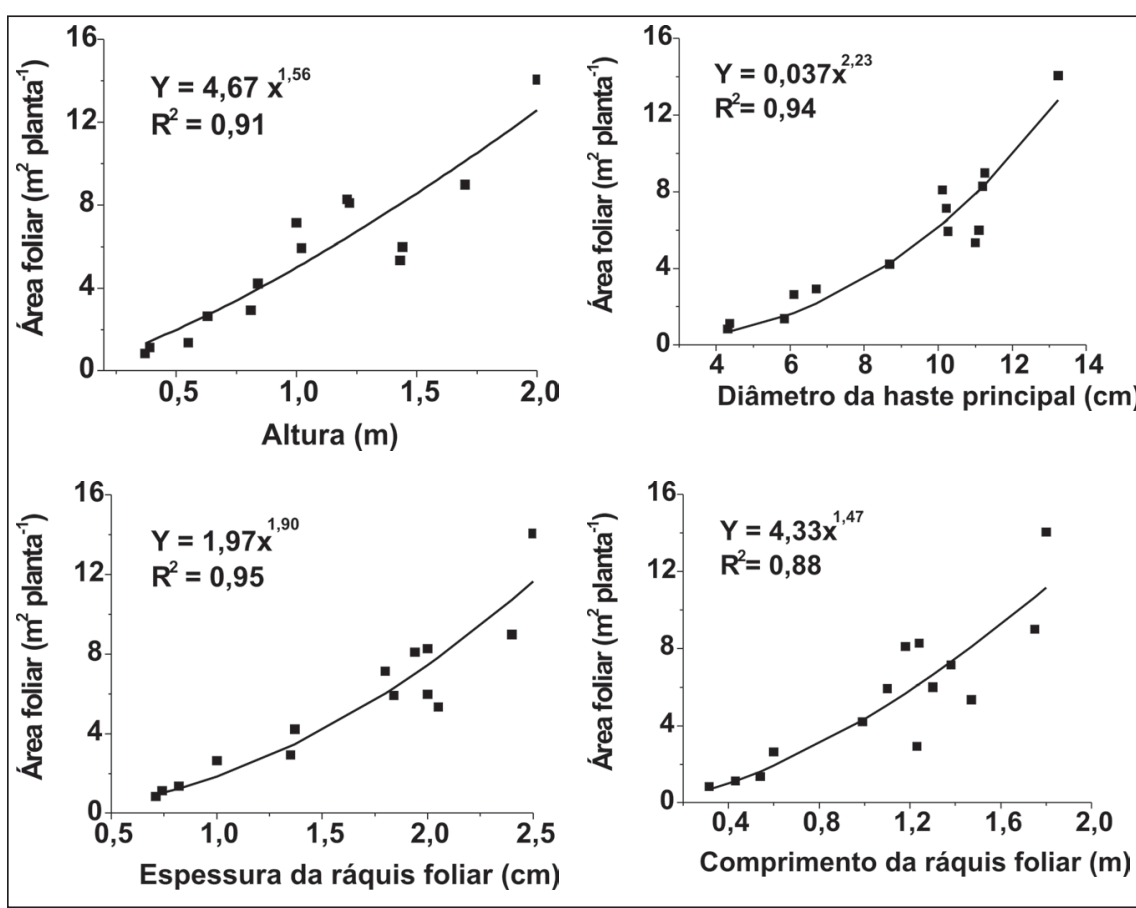

Figura 1. Curvas ajustadas para estimativa da área foliar $\left(\mathrm{m}^{2}\right)$ da pupunheira, em função da altura $(\mathrm{m})$ e diâmetro $(\mathrm{cm})$ da haste principal e da espessura $(\mathrm{cm})$ e comprimento $(\mathrm{m})$ da ráquis foliar (adjusted curves for peach palm leaf area $\left(\mathrm{m}^{2}\right)$ as a function of height $(\mathrm{m})$ and diameter $(\mathrm{cm})$ of main stem and thinckness and length $(\mathrm{m})$ of foliar rachis). Piracicaba, ESALQ, 2002.

ticas de natureza destrutiva e, como variável independente, as características facilmente mensuráveis e não destrutivas (Hyams, 1997). As equações de melhor ajuste foram selecionadas levando-se em conta o coeficiente de determinação (ajustado para o número de parâmetros da regressão, no caso das equações não lineares) e o erro padrão da estimativa, ambos obtidos com o auxílio do programa CurveExpert 1.3 (Hyams, 1997), atentando-se ainda para o significado biológico da equação.

\section{RESULTADOS E DISCUSSÃO}

As plantas selecionadas para o presente estudo estavam com 30 meses no campo. Mesmo nessa idade e recebendo irrigação e adubação adequadas ao cultivo, foram observadas plantas com desenvolvimento muito abaixo do normal. Dessa forma foi possível selecionar desde plantas com $0,37 \mathrm{~m}$ de altura e diâmetro da base inferior a $5 \mathrm{~cm}$, até aquelas plenamente desenvolvidas, com a haste principal medindo $2,00 \mathrm{~m}$ de altura e apresentando diâmetro de $0,13 \mathrm{~m}$. Essa grande amplitude de variação per- mitiu o desenvolvimento de relações alométricas adequadas ao período de crescimento e início de produção de palmito da pupunheira.

Dentre as características mensuradas, a menos variável foi o número de folhas, com coeficiente de variação em torno de $18 \%$ e valores mínimo e máximo de cinco e oito folhas fotossinteticamente ativas, respectivamente. Baixa variabilidade para esse caráter em pupunheira já havia sido reportada anteriormente por Bovi et al. (1992, 1993), Clement (1995) e, mais recentemente, por Ares et al. (2002). Por sua vez, a característica com maior coeficiente de variação $(46,83 \%)$ foi a altura da haste principal, com valores mínimo e máximo de, respectivamente, $0,25 \mathrm{~m}$ e $2,0 \mathrm{~m}$. O diâmetro da haste principal, característica altamente correlacionada à altura (Bovi et al., 1992; Vega et al., 2004) mostrou amplitude de 0,04 a $0,13 \mathrm{~m}$, apresentando menor coeficiente de variação $(32,38 \%)$ que a altura. Das características de folha analisadas, o comprimento da ráquis foliar apresentou maior coeficiente de variação, em torno de $43 \%$, quando comparado à largura $(31,9 \%)$ e espessura $(37,8 \%)$ da ráquis foliar. As variações observadas nas diferentes características avaliadas em plantas com 30 meses de campo e submetidas ao mesmo tratamento (irrigação e adubação) são provavelmente decorrentes da variabilidade genética presente na população de Yurimaguas. e vêm sendo reportada por vários autores (Bovi et al., 1993; Clement, 1995; Ares et al., 2002). Tal variabilidade genética, comum em plantas que sofreram pouco ou nenhum melhoramento genético, acarreta problemas em estudos fitotécnicos, elevando o coeficiente de variação, diminuindo a precisão do experimento e tornando necessário o uso de maior número de repetições e de parcelas com tamanho adequado.

A estimativa da área foliar das hastes analisadas foi efetuada de forma indireta, seguindo o método proposto por Benincasa (1988). Tão logo destacados da ráquis foliar os folíolos da pupunheira se enrolam dificultando a passagem pelo equipamento (LAI 3000). Esse comportamento é comum em palmeiras e faz parte da estratégia da planta para a economia de água. Enrolamento de folíolos em condições de estresse hídrico foi anteriormente observado nessa palmeira por Tucci (2004). De posse da equação $Y=0,0147+0,0129 x\left(R^{2}=0,99\right)$, onde $x$ é o peso seco dos folíolos em gramas e $Y$ é a área foliar em metros quadrados, estimaram-se a área foliar e o índice de área foliar (IAF). Os valores de área foliar variaram de 0,84 a 14,06 $\mathrm{m}^{2}$, com coeficiente de variação de $67,3 \%$. A biomassa foliar média foi de $0,78 \mathrm{~kg}$ planta $^{-1}$, com coeficiente de variação de $88,7 \%$. A biomassa aérea total variou de 0,14 a $4,44 \mathrm{~kg}$ planta $^{-1}$, apresentando coeficiente de variação de $90,5 \%$. Observa-se que os coeficientes de variação são maiores do que aqueles obtidos para as características de fato mensuradas, com valores superiores a $67 \%$. Isto é esperado, visto que essas estimativas são baseadas em mensurações indiretas, e, portanto, sujeitas à adição de erros experimentais inerentes às diferentes etapas. Deve ser esclarecido que os resultados reportados referem-se apenas à haste principal. É sabido (Vega et al., 2004), que a contri- 
buição dos perfilhos para a biomassa aérea total, do estádio de implantação ao início de colheita de palmito (altura variando entre e 0,17 a $2,16 \mathrm{~m}$ ), é pequena e pode ser desprezada. Segundo Vega et al. (2004), nesse estádio de crescimento a dominância da planta-mãe (haste principal) é muito grande, indicando que em plantas com até 2,16 m de altura, estimando-se a biomassa aérea apenas da haste principal obtém-se uma precisão adequada da fitomassa aérea total da touceira.

As relações entre a área foliar e as características mensurados puderam ser expressas por uma série de equações, algumas delas mostrando bom ajuste e significado biológico (Figura 1). Para todas as quatro características avaliadas, o melhor ajuste das curvas foi o potencial, com coeficientes de determinação elevados, com magnitudes de $0,95,0,94$ e 0,91 para espessura da ráquis e diâmetro e altura da haste principal, respectivamente. Para o comprimento de ráquis o coeficiente de determinação foi menor $\left(R^{2}=0,88\right)$, porém ainda estatisticamente significativo $(p<0,01)$. Cabe recordar que o comprimento, a largura e a espessura da ráquis foliar da pupunheira são medidas lineares, fáceis de serem tomadas com razoável precisão e que são amplamente utilizadas em palmeiras (Bovi et al., 1992; Clement, 1995).

Como a variação entre o número de folhas foi muito pequena, apesar das diferentes alturas entre as plantas, foram testados vários ajustes para estimativa da equação de regressão, entretanto, não foi possível um modelo de ajuste significativo. Como este trabalho é parte de um experimento realizado de 1998 a 2002, onde foram estudados o crescimento vegetativo e a produtividade das plantas de pupunha em função de níveis de irrigação e doses de adubação nitrogenada, aplicadas via fertirrigação, Ramos (2002) observou que durante todo o período estudado, o número médio de folhas variou de 5,8 a 8,4 , e, ao final do experimento (dois anos após o plantio, antes do corte das plantas), o número médio de folhas foi de 6,9, período em que foram tomados os parâmetros de crescimento para determinação das equações. Vale ressaltar
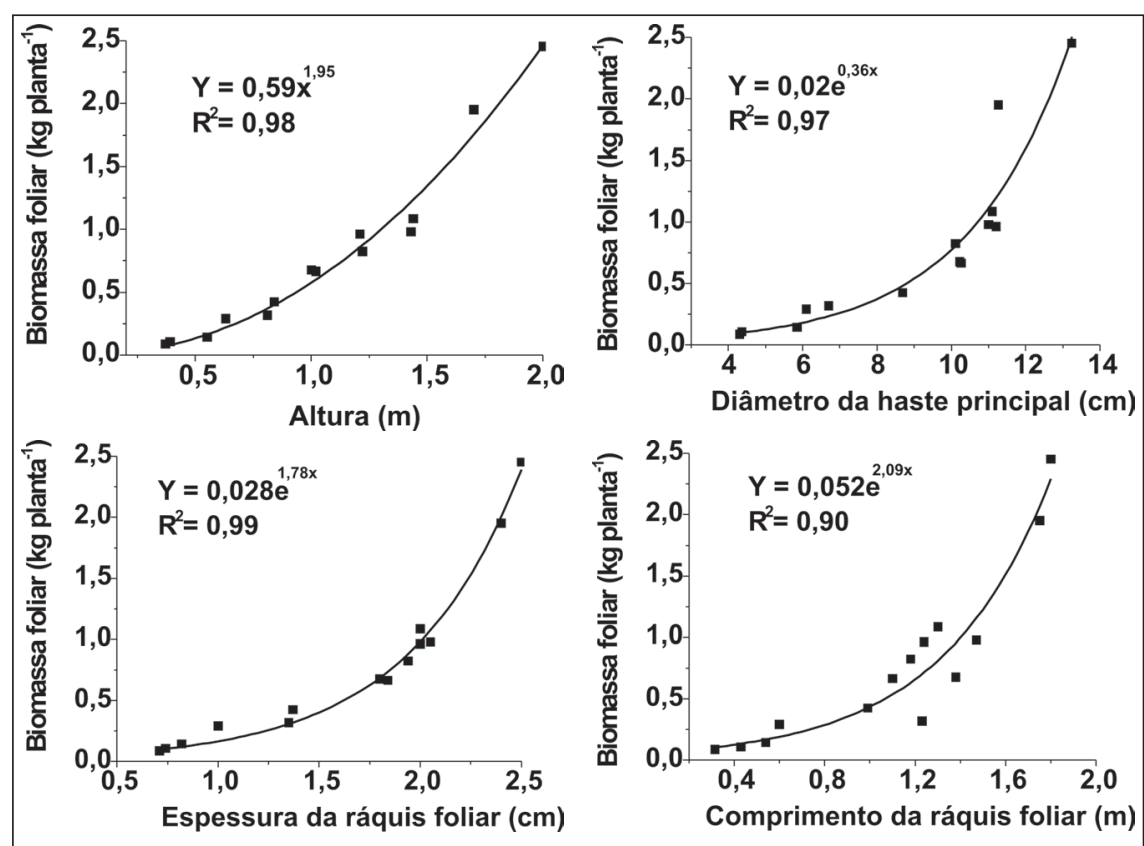

Figura 2. Curvas ajustadas para estimativa da biomassa foliar $\left(\mathrm{kg} \mathrm{planta}^{-1}\right)$ da pupunheira, em relação à altura $(\mathrm{m})$ e diâmetro $(\mathrm{cm})$ da planta e espessura $(\mathrm{cm})$ e comprimento $(\mathrm{m})$ da ráquis foliar, obtida pela relação entre área foliar $\left(\mathrm{m}^{2}\right)$ e peso seco $(\mathrm{g})$ (adjusted curves for peach palm leaf biomass $\left(\mathrm{m}^{2}\right)$ as a function of height $(\mathrm{m})$ and diameter $(\mathrm{cm})$ of main stem and thinckness and length $(\mathrm{m})$ of foliar rachis, obtained of leaf area versus dry weight). Piracicaba, ESALQ, 2002.

que durante o desenvolvimento vegetativo da planta, como parte do processo fisiológico da pupunheira, a cada período, surgem novas folhas e ocorre a morte de folhas mais velhas. Entretanto, certa flutuação do número de folhas, pode estar associada à diminuição acentuada da temperatura média em alguns períodos do ano, conforme observado pela autora. Isso explicaria essa diminuição do número de folhas no período de coleta dos dados, bem como, esta quase uniformidade em relação ao número de folhas, entre as plantas estudadas. Não obstante, é comum a falta de ajuste quando se considera o número de folhas em pupunheira. Vários autores têm relatado esse aspecto, tais como Ares et al. (2002), Bovi et al. (1992), Bovi et al. (1993), Clement, (1995) e Vega et al. (2004). Por esse motivo Clement \& Bovi (2000) sugerem, além da contagem do número de folhas, a inclusão de outros caracteres a elas relacionados, especialmente aqueles relacionados às dimensões do limbo foliar.

A biomassa foliar (Figura 2) apresentou forte relação com a altura e o diâmetro da haste principal, assim como com a espessura e o comprimento da ráquis foliar, com altos coeficientes de determinação $(0,98 ; 0,97 ; 0,99$ e 0,90 , respectivamente). Entretanto, somente para altura, o melhor ajuste foi o potencial $\left(Y=a x^{b}\right)$. Para diâmetro da haste principal, e para espessura e comprimento de ráquis, o melhor ajuste foi $o$ exponencial $\left(Y=a^{b x}\right)$, devido aos pontos representados pelas plantas com altura entre 1,70 e 2,0 m que resultaram em biomassa bem superior às demais plantas. Plantas nessa faixa de altura possuíam significativamente maior número de folhas, além destas apresentarem maiores dimensões, avaliadas aqui pelo comprimento, largura e espessura da ráquis foliar.

Observa-se que as equações de melhor ajuste para a estimativa da biomassa aérea total da haste principal em relação à altura e ao diâmetro das mesmas, assim como em relação ao comprimento e à espessura da ráquis foliar (Figura 3) foram semelhantes às obtidas anteriormente para a biomassa foliar, com ajuste potencial para a altura e exponencial para os demais caracteres. Os coeficientes de determinação tam- 

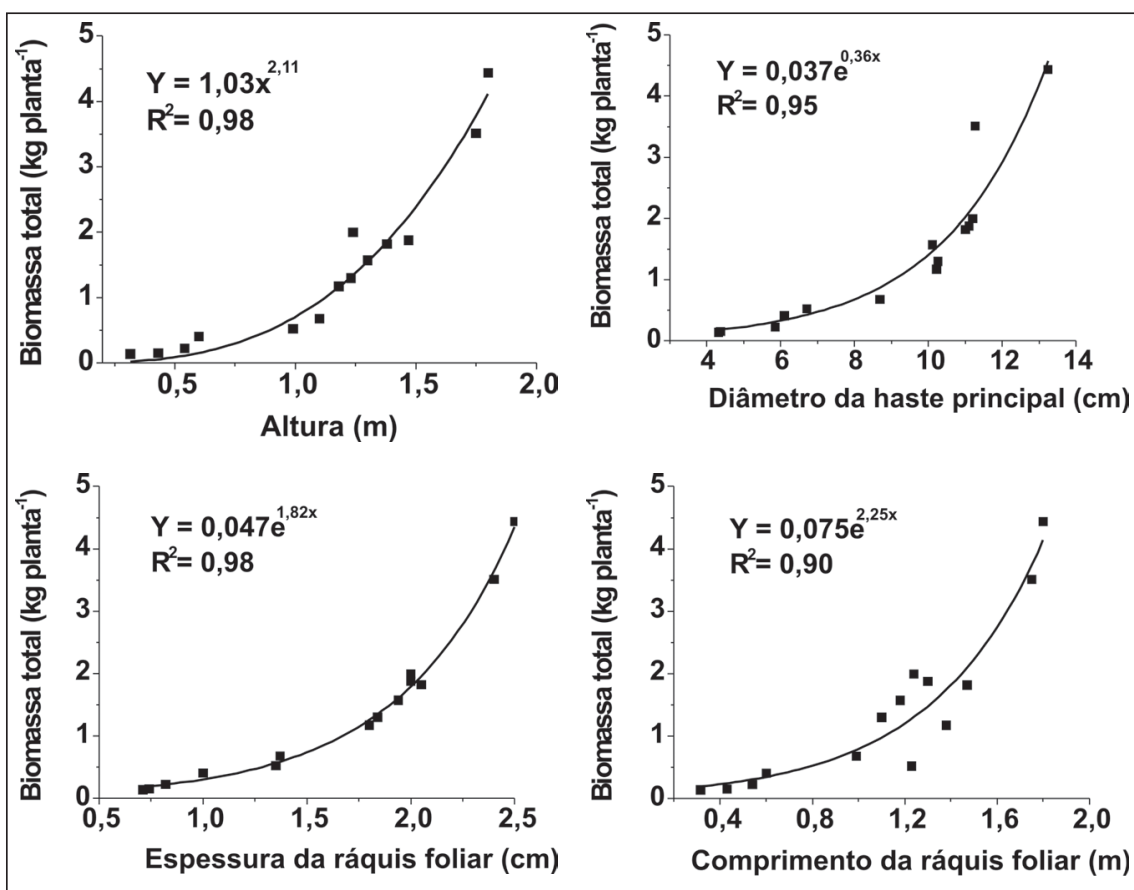

Figura 3. Curvas ajustadas para estimativa da biomassa aérea total $\left(\mathrm{kg} \mathrm{planta}^{-1}\right)$ da pupunheira, em relação à altura $(\mathrm{m})$ e diâmetro da haste principal $(\mathrm{cm})$ e espessura $(\mathrm{cm})$ e comprimento $(\mathrm{m})$ da ráquis foliar, obtida pela relação entre área foliar $\left(\mathrm{m}^{2}\right)$ e peso seco $(\mathrm{g})$ (adjusted curves for peach palm total área leaf biomass $\left(\mathrm{m}^{2}\right)$ as a function of height $(\mathrm{m})$ and diameter $(\mathrm{cm})$ of main stem and thinckness and length $(\mathrm{m})$ of foliar rachis, obtained of leaf area versus dry weight). Piracicaba, ESALQ, 2002.

bém foram elevados, com magnitudes de 0,98 para altura da haste principal e espessura da ráquis foliar; 0,95 para diâmetro da planta e 0,90 para comprimento da folha. Esses resultados eram esperados, visto que a biomassa aérea total é resultante da biomassa foliar, composta pelas folhas externas (pecíolos e limbos), acrescida do peso do estipe, do palmito e das bainhas internas das folhas que protegem o palmito.

Conforme esperado, os coeficientes de determinação foram também elevados quando da relação entre a área foliar e as biomassas foliar $\left(R^{2}=0,94\right.$ para $\left.Y=0,076 x^{1,313}\right)$ e total $\left(\mathrm{R}^{2}=0,90\right.$ para $Y$ $\left.=0,136 x^{1,324}\right)$ da haste principal de pupunheira (gráficos não apresentados). Resultados semelhantes foram obtidos anteriormente por Szott et al. (1993) e recentemente por Vega et al. (2004), com população de mesma origem genética. No entanto, como discutido por estes últimos autores, a estimativa da área foliar é feita quase sempre de forma indireta, demandando análises destrutivas a campo em amostra representativa da população em estudo, seguida de trabalho considerável execu- tado posteriormente em laboratório. Ainda mais, pela particularidade dos folíolos excisados da pupunheira de se enrolarem quando destacados da ráquis foliar e, por isso, não podem ser utilizados diretamente no medidor de área foliar. Com isso, adiciona-se ao processo uma operação demorada e delicada de desenho dos folíolos em papel e recorte dos contornos, para só então medir-se a área foliar. Isso tudo, além da demora adicional, acarreta erros experimentais dificilmente eliminados nas etapas posteriores. Dessa forma, há necessidade de se identificarem características mais facilmente mensuráveis, de preferência de natureza não destrutiva, e que se correlacionam adequadamente com a biomassa.

No presente trabalho não foram encontrados ajustes satisfatórios quando se considerou a relação entre o número de folhas e a área foliar ou as biomassas foliar e aérea total da pupunheira. Resultados semelhantes foram obtidos anteriormente por Bovi et al. (1993) e mais recentemente por Vega et al. (2004), indicando a pouca utilidade desse caráter quando analisado separadamente (apenas número), sem levar em conta também suas dimensões (comprimento e largura). No entanto, merece destaque a relação encontrada entre a espessura da ráquis foliar e a área foliar e/ou biomassas. A espessura da ráquis foliar, medida no ponto da inserção dos primeiros folíolos, é um caráter de fácil mensuração (com auxílio de régua, paquímetro convencional ou digital), apresentando natureza não destrutiva. Por meio de equações não lineares simples $\left(Y=a x^{b}\right.$ e/ou $\left.Y=a^{b x}\right)$ pode-se utilizálo para estimar, com elevada precisão $\left(\mathrm{R}^{2}>0,95 ; \mathrm{P}<0,01\right)$, tanto a área foliar quanto às biomassas foliar e total aérea da pupunheira. Apresenta, portanto, maior utilidade que o diâmetro ou a altura da haste, caracteres indiretos considerados, até então, como ideais para estimativas indiretas de biomassa em pupunheira (Ares et al. 2002).

\section{AGRADECIMENTOS}

Este trabalho é parte da dissertação do primeiro autor, com projeto (98/ 13229-4) financiado pela FAPESP.

\section{REFERÊNCIAS}

ARES A; QUESADA JP; BONICHE J; YOST RS; MOLINA E; SMYTH J. 2002. Allometric relationships in Bactris gasipaes for heart-ofpalm production agroecosystems in Costa Rica. Journal of Agricultural Science. 138: 285-292.

BENINCASA MMP. 1988. Análise do crescimento de plantas: noções básicas. Jaboticabal: FUNEP, 42 p. (Boletim Técnico 467 a).

BOVI MLA. 1998. Palmito pupunha informações básicas para cultivo. Campinas: IAC, $50 \mathrm{p}$. (Boletim Técnico 173).

BOVI MLA; SAES LA, GODOY JUNIOR G. 1992. Correlações fenotípicas entre caracteres não destrutíveis e palmito em pupunheiras. Revista Turrialba. 42: 382-390.

BOVI MLA; GODOY JUNIOR G; CAMARGO SB; SPIERING SH. 1993. Caracteres indiretos na seleção de pupunheiras inermes (Bactris gasipaes H.B.K.) para palmito. In: CONGRESO INTERNACIONAL SOBRE BIOLOGIA, AGRONOMIA E INDUSTRIALIZACION DE PIJUAYO, 4, Iquitos. Anais... San José: UFCR, p.163-176.

CHILD R. 1974. Coconuts (Cocos nucifera L.). 2nd. ed. London: Longman, 335 p.

CLEMENT CR. 1995. Growth and analysis of pejibaye (Bactris gasipaes Kunth, Palmae) in Hawaii, Honolul. University of Hawaii at Manoa. $221 \mathrm{p}$ (Tese doutorado). 
CLEMENT CR; BOVI MLA. 2000. Padronização de medidas de crescimento e produção em experimentos com pupunheira para palmito. Acta Amazonica: 30: 349-362.

CLEMENT CR; MORA URPÍ J; COSTA SS. 1985.Estimación del area foliar del pejibaye (Bactris gasipaes H.B.K.). Revista de Biologia Tropical: 33:99-105.

HARDON JJ; WILLIAMS CN; WASTSON I. 1969. Leaf area and yield of the oil palm in Malaysia. Experimental Agriculture 5: 25-32.

HARTLEY CWS. 1977. The oil palm (Elaeis guineensis Jacq.), $2^{\text {nd }}$. ed. London: Logman, $806 \mathrm{p}$.

HYAMS D. CurveExpert 1.3. 1997. A comprehensive curve fitting system for Windows. Starkville, [software]. disponível em: <http://wwwebicom.net/ dhyams>.

LAMADE E. 1997. Métode rapide de mesure de l'indice foliaire du palmier é huile. Plantation, recherché, développement 4: 385-391.
MARTEL JHI; CLEMENT CR. 1986/87. Comparação preliminar da área foliar de três acessos de pupunha (Bactris gasipaes Kunth) oriundos de três populações distintas da Amazônia Ocidental. Acta Amazônica 16/ 17:13-18.

OMETTO JC. 1981. Bioclimatologia vegetal. São Paulo: Agronômica Ceres, 440 p.

RAMOS A. 2002. Análise do desenvolvimento vegetativo e produtividade da palmeira pupunha (Bactris gasipaes Kunth) sob níveis de irrigação e adubação nitrogenada. Piracicaba: USP-ESALQ. 113p (Tese doutorado).

STEEL RG; TORRIE JH. 1980. Principles and procedures of statistics. New York: MacGrawHill, 632 p.
SZOTT LT; AREVALO L; PEREZ J, 1993. Allometric relationships in pijuayo (Bactris gasipaes H.B.K.). In: CONGRESO INTERNACIONAL SOBRE BIOLOGIA, AGRONOMIA E INDUSTRIALIZACION DEL PIJUAYO, 4. Iquitos. Anais. San José: UFCR, p.91-114.

TUCCI MLS. 2004. Variação estacional do crescimento e de trocas gasosas em pupunheira (Bactris gasipaes Kunth). UNICAMP - Instituto de Biologia. 168p (Tese doutorado).

UNIVERSIDADE FEDERAL DE VIÇOSA. 1993. Manual de utilização do programa SAEG - Sistema para análises estatísticas e genéticas. Viçosa: UFV, 59 p.

VEGA FVA; BOVI MLA; SPIERING SH; GODOY JÚNIOR G. 2004.Relações alométricas para estimativa da fitomassa aérea em pupunheira. Horticultura Brasileira 22:104-108. 